\title{
Physical and Mechanical Characteristics of Kevlar Fiber-reinforced PC/ABS Composites
}

\author{
Sarawut Rimdusit ${ }^{1, *}$, Parkpoom Lorjia ${ }^{1}$, Kuljira Sujirote ${ }^{2}$, and Sunan Tiptipakorn ${ }^{3}$ \\ 1 Polymer Engineering Laboratory, Department of Chemical Engineering, Faculty of Engineering, \\ Chulalongkorn University, Bangkok 10330, Thailand \\ 2 National Metal and Materials Technology Center, 114 Thailand Science Park, Klong Luang, \\ Pathumthani12120, Thailand \\ 3 Department of Chemistry, Faculty of Liberal Arts and Science, Kasetsart University, Kamphaeng \\ Saen, Nakhon Pathom 73140, Thailand \\ E-mail address: sarawut.r@ chula.ac.th ${ }^{*}$
}

\begin{abstract}
In this research, the laminated composites between the blend of polycarbonate (PC)/acrylonitrile-butadiene-styrene (ABS) and Kevlar fiber were prepared. The flexural and tensile properties of PC/ABS alloy and its composites were determined using a universal testing machine. The synergistic behavior of flexural modulus was observed for all regions of PC contents, while the synergism of flexural strength and tensile strength were found in some PC contents. It was found that the optimum weight ratio of PC:ABS was 60:40. In the Kevlar Fiber-reinforced PC/ABS composite system at $\mathrm{PC}: \mathrm{ABS}$ of $60: 40$, both flexural modulus and strength were increased with matrix contents. Additionally, the flexural strength drastically increased with the matrix content and then reached the maximum value of $167 \mathrm{MPa}$ at the matrix content of $33.4 \mathrm{wt} \%$. The results from peel test, water contact measurement, and scanning electron microscopy (SEM) reveal that the interfacial adhesion between the Kevlar fiber and the polymer matrix could be improved by increasing the PC content in the matrix.
\end{abstract}

Keywords: Polycarbonate, acrylonitrile-butadiene-styrene, composite, Kevlar fiber.

ENGINEERING JOURNAL Volume 16 Issue 1

Received 3 September 2011

Accepted 27 October 2011

Published 1 January 2012

Online at http://www.engj.org

DOI:10.4186/ej.2012.16.1.57 


\section{Introduction}

It has been well known that the alloy between bisphenol A polycarbonate (PC) and acrylonitrilebutadiene-styrene (ABS) is one of the most important commercial products for engineering applications [1-3]. The alloy, possessing many preferable properties, does not only minimize the disadvantages of pure PC (i.e. low chemical resistance, difficulty to process, high notch sensitivity, and easiness for stress cracking), but also introduce the other useful properties, such as glossiness and lowtemperature toughness [4]. There are a number of patents and researches concerning the blend have been issued in the past [5-15], but the knowledge about its behavior is still limited because of the complexity of the system [16].

In many composite systems, the PC/ABS alloys have been selected to be used as matrix due to its ability to be tailor-made by varying their composition. Up till now, there are several researches focused on the composite of the PC/ABS matrix and reinforcing fillers such as carbon fiber, glass fiber, and montmorillonite [17-19]. However, there has not been a study on the PC/ABS alloy reinforced with Kevlar aramid fiber. The Kevlar fiber renders many outstanding properties. For instance, it has higher specific tensile strength than steel wire, industrial nylon, and polyester yarns. It also has a much higher tensile modulus than fiberglass, nylon, and polyester fibers. Furthermore, the Kevlar fiber possesses lower density than steel wire and glass fiber [20].

The aim of this study is to investigate the effects of the PC contents on the flexural and tensile properties of the PC/ABS alloy and the Kevlar-reinforced PC/ABS composite. Additionally, the interface between the matrix and the Kevlar fiber was observed via scanning electron microscope (SEM)

\section{Experimental}

\subsection{Materials}

Polycarbonate (PC) under the trade name of Makrolon ${ }^{\circledR} 2800$ was supplied from Bayer Co., Ltd., while Acrylonitrile-Butadiene-Styrene graft copolymer (ABS), under the trade name of Lustran ${ }^{\circledR} 440$ was provided from Lanxess (Thailand) Co., Ltd. The aramid fiber used in this study was Kevlar-29 plain weave type. The weight average molecular weights $\left(\bar{M}_{W}\right)$, number average molecular weights $\left(\bar{M}_{N}\right)$ and polydispersity index (PDI) of the chemicals are shown in Table 1.

Table 1. Average molecular weight of PC and ABS determined by gel permeation chromatography.

\begin{tabular}{lccc}
\hline Component & $\bar{M}_{W}(\mathbf{g} / \mathbf{m o l})$ & $\bar{M}_{N}(\mathbf{g} / \mathbf{m o l})$ & PDI \\
\hline PC2800 & 50482 & 27571 & 1.83 \\
ABS & 105251 & 51052 & 2.06 \\
\hline
\end{tabular}

\subsection{Preparation of polymer alloy}

PC and ABS were dried at $100{ }^{\circ} \mathrm{C}$ for at least 6 hours in an air oven before PC was blended at the PC/ABS ratio varied from $80 / 20$ to 20/80. Melt mixing of PC and ABS was carried out by a twin screw extruder (Rheocord 300p of Haake Inc.). The diameter and the length of the screw in the extruder were $16 \mathrm{~mm}$ and $400 \mathrm{~mm}$, respectively. From the die head, the temperatures of five heating zones were set to $250,250,240,230$ and $220^{\circ} \mathrm{C}$, respectively. The screw speed was fixed at $90 \mathrm{rpm}$.

\subsection{Processing for testing samples}

The blending pellets of $\mathrm{PC}$ and $\mathrm{ABS}$ were dried at $100^{\circ} \mathrm{C}$ for at least 6 hours in an air oven. Then they were processed by using a compression molder at $250^{\circ} \mathrm{C}$ under the pressure of $250 \mathrm{~kg} / \mathrm{cm}^{2}$. The dimension of samples for flexural test was $25 \mathrm{~mm} \times 60 \mathrm{~mm} \times 3 \mathrm{~mm}$. 
PC/ABS film was produced using the same twin screws extruder. In the process, the extruder was equipped with film blowing die (LDPE-type die) with a diameter of $35 \mathrm{~mm}$ and a die gap of $1 \mathrm{~mm}$. The molten polymer was extruded through the die and then was drawn up by nip rolls without air blowing. The molten polymer was cooled using an air cooling ring. Temperatures of five zones were set at 255, $250,240,230$ and $220^{\circ} \mathrm{C}$ from die side, respectively. Screw speed was fixed at $90 \mathrm{rpm}$. The thickness of film was controlled by nip rolls take-up velocity. The draw ratio was estimated to be 10 .

\subsection{Composite processing}

Kevlar-reinforced PC/ABS composites were manufactured by film-stacking method. The woven Kevlar fiber and PC/ABS film were cut and dried in an air oven. Then, the woven fibers and PC/ABS films were stacked alternately with a designed number of layers. The composites were made by hot pressing with compression molder at the processing temperature of $220^{\circ} \mathrm{C}$ and the pressure of $25 \mathrm{MPa}$ for 30 minutes. The contact angle of each sample has been tested in order to control the wettability.

\subsection{Sample characterizations}

Flexural properties of the composites were determined using a universal testing machine (Instron, model 5567). Flexural tests were conducted according to ASTM D790M-93 standard. The test method used was a three-point loading by the support span of $48 \mathrm{~mm}$. The crosshead speed during the flexural testing was $1.2 \mathrm{~mm} / \mathrm{min}$. At least five samples were used to determine the average property values. The tensile test was performed according to ASTM D638. The specimens of the test were fabricated in dogbone shape.

The peel strengths of the composites were measured by the $180^{\circ}$ peel test according to ASTM D903. At least five samples were used to determine the average property values.

The polymer matrices surfaces were characterized by the measurement of water contact angle measurement. The water contact angle is an indicator of the polarity and fiber wettability of the matrices which was measured by a sessile drop method at room temperature using a contact angle meter (Cam-plus Micro, Tantec Inc.). Purified water droplet $(2 \mu \mathrm{l})$ was dropped on the sample surface by a micro-syringe and then the contact angle was measured immediately after placement on the polymer surface. Each reported value was averaged from 5-10 measurements.

The relationship between composition and intrinsic morphological characteristics of the blending systems and also the interfacial interaction between Kevlar fiber and polymer matrix was studied employing scanning electron microscope (JEOL-JSM 5800LV) at an acceleration voltage of $15 \mathrm{kV}$. The delamination surfaces of the composite specimens were gold sputtered ( $3 \mathrm{~nm}$ thickness) and dried in vacuum at room temperature. The obtained micrographs were used to investigate qualitatively the interfacial interaction between the fiber and the PC/ABS matrix.

In order to investigate morphology of PC/ABS blends, the flexural tested specimens were etched in an aqueous $\mathrm{NaOH}$ solution $(30 \% \mathrm{w} / \mathrm{v})$ at $150^{\circ} \mathrm{C}$ for 20 minutes to remove the PC fraction from their surfaces before obtaining the SEM micrographs.

\section{Results and Discussion}

\subsection{Mechanical properties of PC/ABS matrix}

Figure 1 shows the flexural modulus and strength of PC/ABS as a function of PC content. The flexural modulus of the PC/ABS alloys at various PC contents exhibited a positive deviation from the mixing rule. The flexural modulus in the alloy system at $40 \mathrm{wt} \%$ of PC was exhibited the highest value of 2.7 $\mathrm{GPa}$, which was higher than the moduli of the parent polymers (2.4 GPa of PC and 2.5 GPa of ABS). The positive-deviation phenomenon in the modulus of these alloys could also be seen in some previous works (with different types of ABS) such as in the work of Lombardo et al. [21] and Menon et al. [22]. The existence of the inter-zones between the PC and ABS phases as discussed by Menon et al. [22] was probably attributed to the very good adhesion at the interface between the two components $[16,19]$. The authors hypothesized the invoked diffusion of low $\bar{M}_{W}$ species of SAN (Styrene-acrylonitrile) towards the PC domains resulting in certain compatibility between the SAN contained in the ABS and 
the PC. Additionally, it can be seen that the flexural strengths of PC/ABS were found to increase with increasing $\mathrm{PC}$ in the blend (from $72 \mathrm{MPa}$ of pure $\mathrm{ABS}$ to $100 \mathrm{MPa}$ of pure PC). In addition, the strength of PC/ABS blend exhibited negative deviation from the mixing rule when the PC content was less than about $60 \mathrm{wt} \%$ of PC and then turned to positive deviation from the rule when the PC content was higher than $60 \mathrm{wt} \%$.

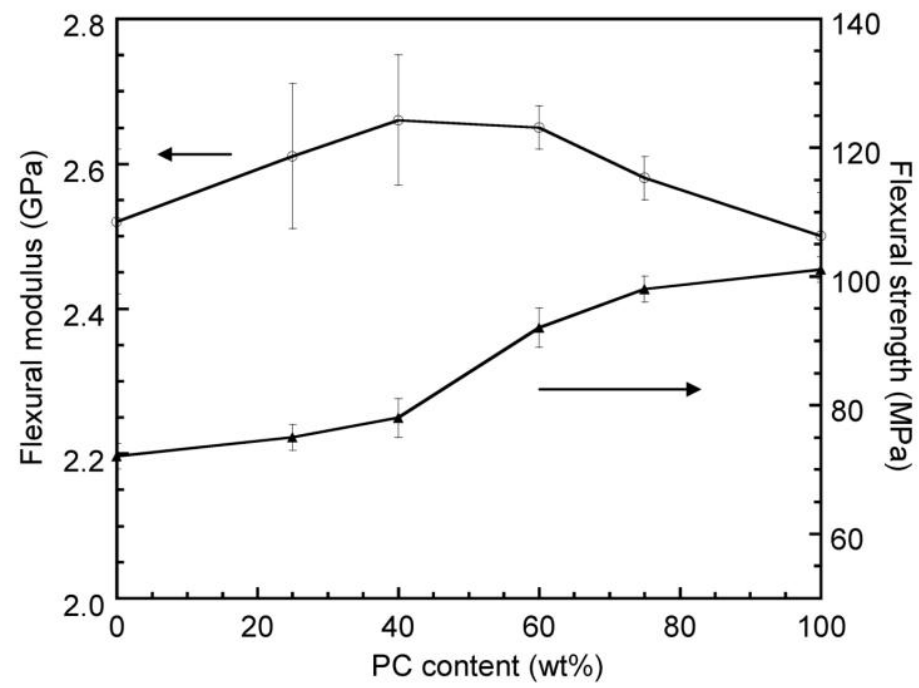

Fig. 1. Flexural modulus and strength of PC/ABS blends at various PC contents in PC/ABS matrix.

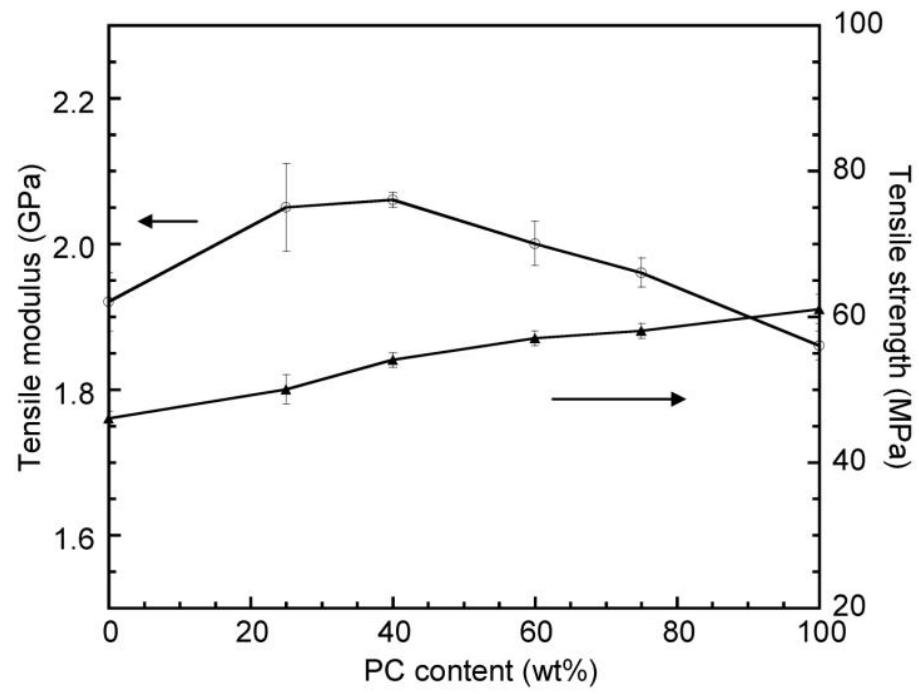

Fig. 2. Tensile modulus and strength of PC/ABS blends at various PC contents in PC/ABS matrix.

The relationships between the tensile properties of PC/ABS blends and PC content are shown in Fig. 2. It can be seen that the tensile modulus also exhibited positive deviation; furthermore, the highest modulus value of $2.1 \mathrm{GPa}$ was observed in the blend system at approximately $40 \mathrm{wt} \%$ of PC (the same PC content for the synergistic behavior in flexural modulus). It can be seen that the tensile strength increased with increasing PC content in the PC/ABS blend from $46 \mathrm{MPa}$ to $60 \mathrm{MPa}$ of pure ABS and $\mathrm{PC}$ respectively. As seen in the figure, the increasing rate of tensile strength value was found to change at the composition range between 40 and $60 \mathrm{wt} \%$ of PC. In addition, the strength drastically increased from $46 \mathrm{MPa}$ (of pure ABS) to $54 \mathrm{MPa}$ (of the blend with $40 \mathrm{wt} \%$ of PC). For the further PC addition, the strength gradually increased to $60 \mathrm{MPa}$ of pure PC. Moreover, elongation at break of the PC/ABS blends shown in Fig. 3 virtually unchanged in the range of $0-40 \mathrm{wt} \%$ of PC. The breaking strains at this range of PC contents were between 5 and $9 \%$. In the blends at the PC content of beyond $40 \mathrm{wt} \%$, the breaking strain sharply increased with the PC content; the maximum value of $55 \%$ was found at the PC 
content of $75 \mathrm{wt} \%$. Beyond this content, the breaking strain gradually decreased to $43 \%$ which is the value of pure PC. The variation of our breaking strain value corresponds with the result of B.S. Lombardo et al. [21].

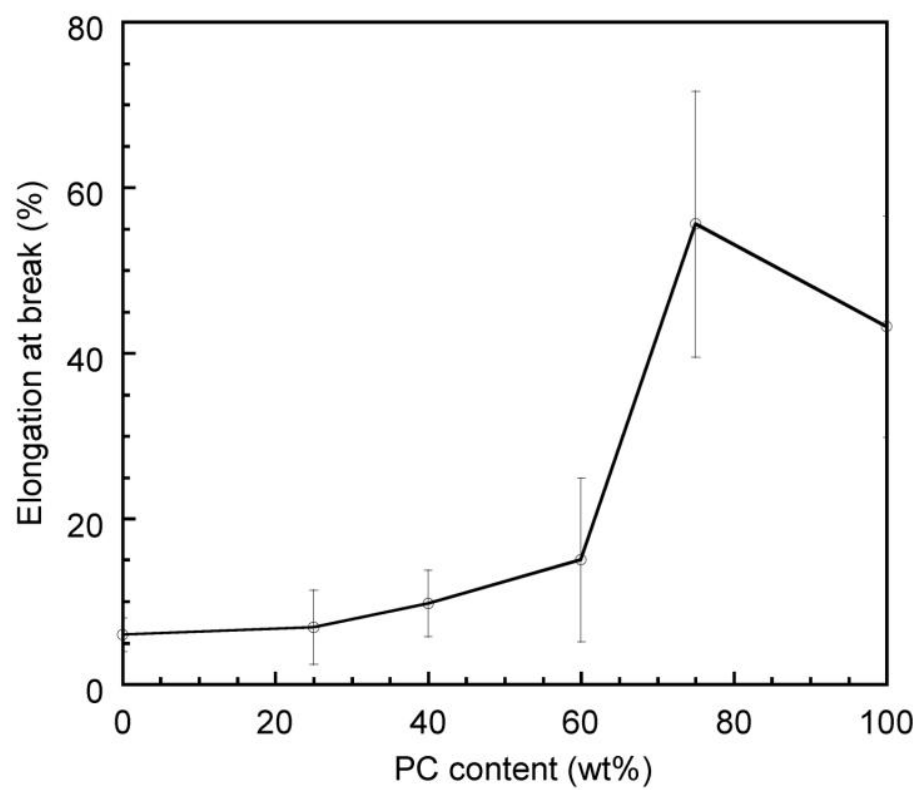

Fig. 3. Elongation at break of PC/ABS blends at various PC contents in PC/ABS matrix.

These remarkable behaviors of both flexural and tensile strengths of the blend involve with the phase transition. Normally, in the mixing of two immiscible polymers, two phase structure is usually formed. The component that occupy most volume of structure is called continuous phase and another phase is called dispersed phase. From Fig. 1, flexural strength of the blend displayed negative deviation from the mixing rule up to about $60 \mathrm{wt} \%$ of PC. This region ABS was found to be a continuous phase because there is an ABS-rich phase, and ABS also has lower viscosity than PC. Therefore, ABS trends to be encapsulation species. For further addition of $\mathrm{PC}$, the strength turned to be positive deviation from the rule of mixing. In this region, $\mathrm{PC}$ performed as a continuous phase.

As seen in Figs. 1 and 2, both flexural and tensile modulus of the blend exhibited synergistic behavior. This phenomenon could be attributed to the fact that the low molecular weight fraction of ABS was able to dissolve in the PC domain, resulting in certain compatibility between the SAN contained in the ABS and the PC itself, and thus strengthening the ABS phase. This reason can be used to explain why the modulus of $\mathrm{PC} / \mathrm{ABS}$ blends exhibited positive deviation from the rule of mixing.

\subsection{Composite characterizations}

\subsubsection{Mechanical property measurement}

To determine the most optimal polymer matrix content in the composite, the PC/ABS (60/40) films with varied thicknesses of $30,40,50,100,150$, and $200 \mu \mathrm{m}$ were used for film stacking processing in the composite fabrication. These thicknesses made the PC/ABS matrix contents be 16.0, 19.2, 26.9, $33.4,46.9$, and $52.2 \mathrm{wt} \%$ respectively. Figure 4 reveals the flexural modulus and strength of Kevlar/PC/ABS composite as a function of the above matrix contents. Additionally, the flexural strength sharply increases with the matrix content and then reaches the maximum value of $167 \mathrm{MPa}$ at the matrix content of $33.4 \mathrm{wt} \%$. Beyond this content, the strength gradually decreases with increasing the matrix fraction. In addition, the flexural modulus of the composite as a function of matrix content also sharply increases with the matrix content and the highest modulus with the value of $15 \mathrm{GPa}$ was acquired from the composite with the matrix content of $26.9 \mathrm{wt} \%$. However, with increasing the matrix content beyond this ratio the modulus also decreases. The drastic increase of the flexural strength and modulus was due to the reduction of void content by increasing the quantity of polymer matrix to be able to penetrate into the Kevlar fabric. This might lead to the enhancement of the interaction between 
the matrix and fiber. In the composite processing with the matrix content between 26.9-33.4 wt\%, the polymer matrix was penetrated into the fabric at the highest level. However, the mechanical properties decreased for a further increase in the amount of the matrix.

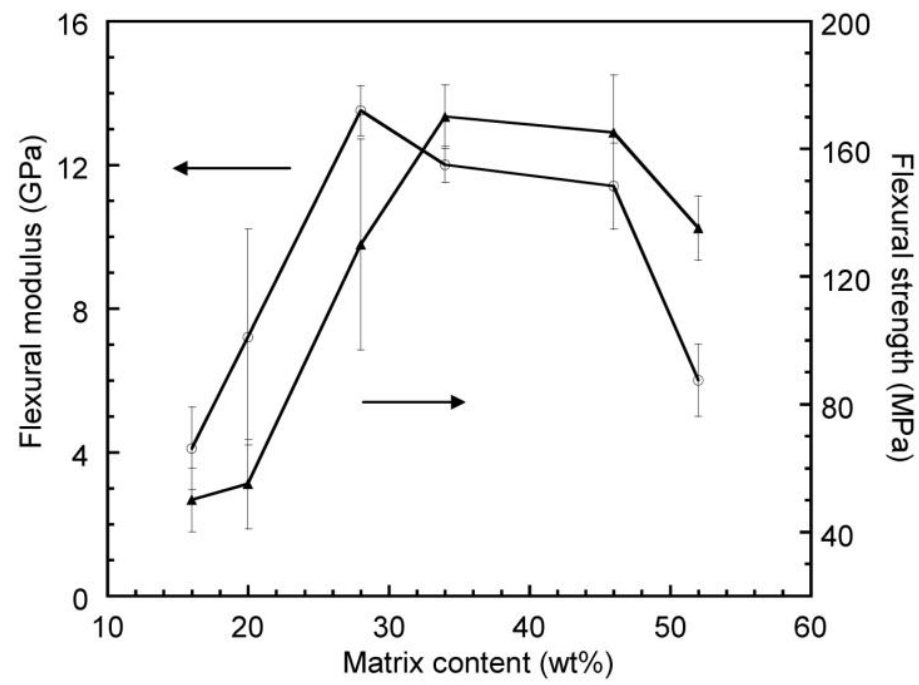

Fig. 4. Flexural modulus and strength of Kevlar/PC/ABS composite at various matrix contents.

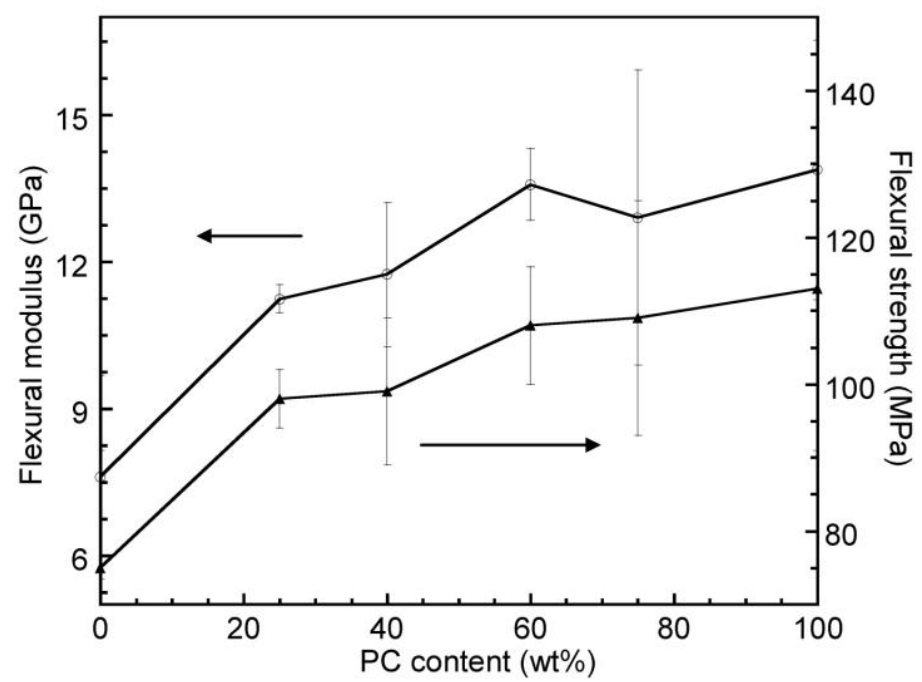

Fig. 5. Flexural properties of Kevlar-reinforced PC/ABS composites as a function of PC content in matrix.

The mechanical properties of fiber reinforced composite depend on several factors such as mechanical properties of each component and the fiber volume fraction. One of the important factors is the adhesion between the fiber and matrix. Figure 5 shows the flexural modulus and strength of Kevlarreinforced PC/ABS composites as a function of PC content in the blend matrix. It can be seen that the modulus of the composites was systematically increased from $7.6 \mathrm{GPa}$ (using pure $\mathrm{ABS}$ as a matrix) to 13.8 $\mathrm{GPa}$ (using pure $\mathrm{PC}$ as a matrix). From the prior experiment, PC/ABS blends exhibited synergistic behavior in flexural modulus. Therefore, the blends moduli were higher than those of the neat PC and ABS. However, the synergism was not observed in the case of Kevlar-reinforced PC/ABS. This discrepancy might be due to the fact that for the composite system, the adhesion between the reinforcing fiber and the PC/ABS matrices could play a major role in the flexural modulus of the composite. The flexural modulus curve implies that the adhesion between the Kevlar and the PC/ABS matrices could increase with increasing PC content in the matrices. It can be seen that flexural strength of the composites, which increased from $75 \mathrm{MPa}$ (using pure ABS as a matrix) to $113 \mathrm{MPa}$ (using pure PC as a matrix). The increase of the flexural strength of the composites might be influenced by the interfacial strength between the reinforced fiber and PC/ABS matrix and the flexural strength of the 
matrix itself. The effects of interfacial strength on the mechanical properties of the composites could be observed in other systems such as in sisal-epoxy composites [23] and single-walled carbon nanotube reinforced copper matrix [24].

\subsubsection{Investigation of adhesion between Kevlar fiber and PC/ABS matrices}

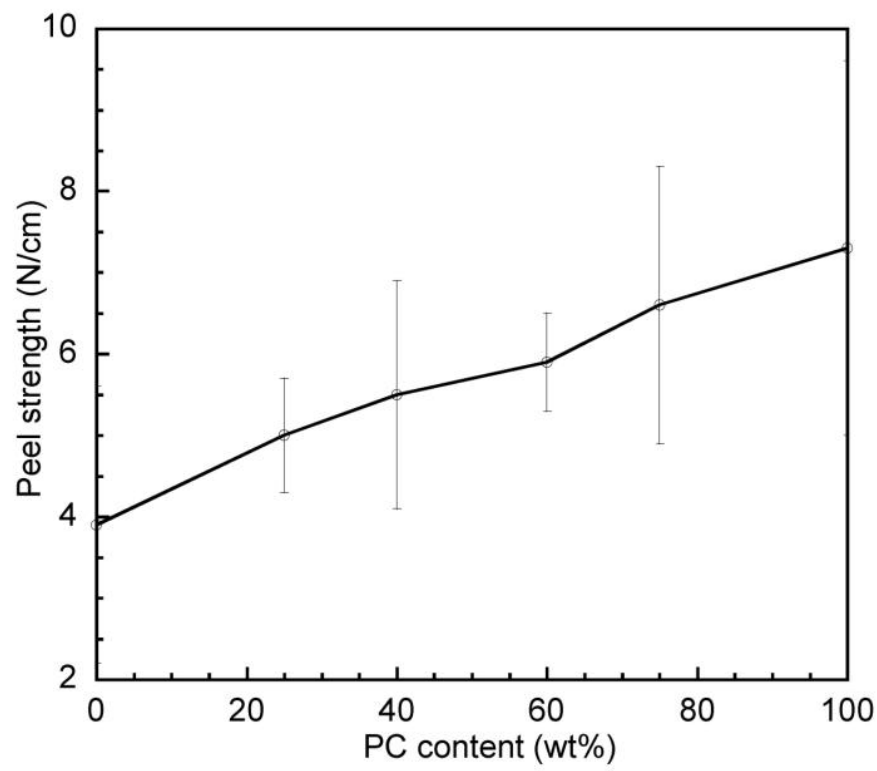

Fig. 6. Peel strength of the Kevlar-reinforced PC/ABS composites as a function of PC content in matrix.

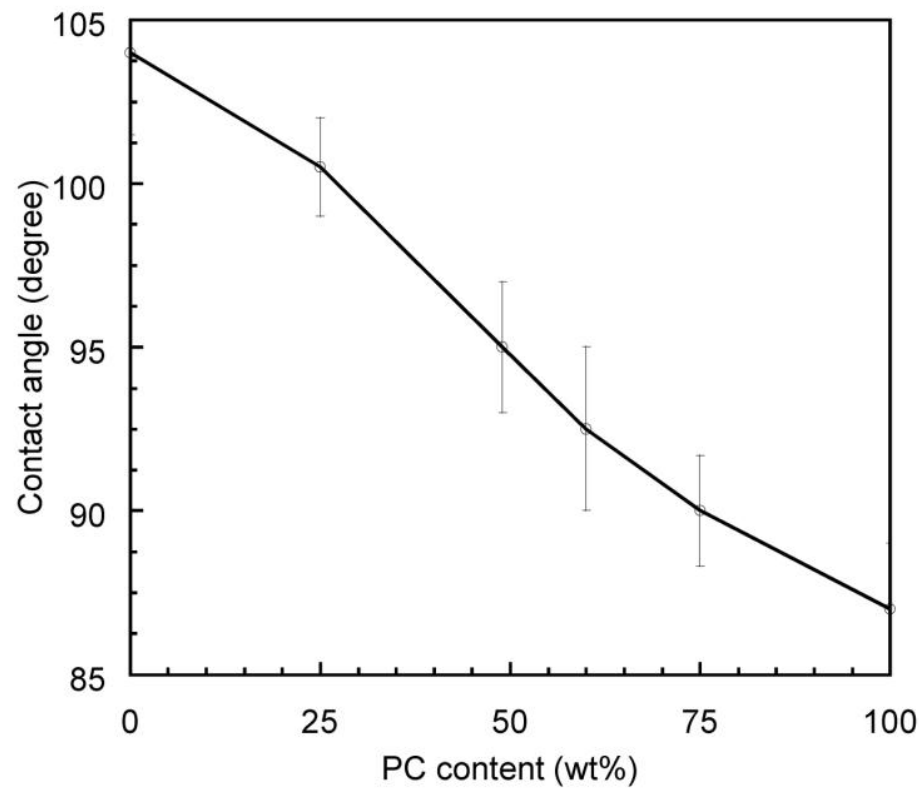

Fig. 7. Water contact angles of PC/ABS matrices at various compositions.

In order to confirm the flexural results and to investigate the adhesion between the Kevlar fiber and PC/ABS matrices, peel strength of the composites had also been evaluated. Figure 6 illustrates the peel strength of the composites as a function of PC content in the matrix. As seen in the figure, the peel strength gradually increased from $3.9 \mathrm{~N} / \mathrm{cm}$ (using pure $\mathrm{ABS}$ as a matrix) to $7.3 \mathrm{~N} / \mathrm{cm}$ (using pure $\mathrm{PC}$ as a matrix). This suggested that the interfacial adhesion between the Kevlar fiber and the polymer matrix could be improved by increasing the $\mathrm{PC}$ content in the matrix. The results also correspond with an increase of flexural modulus and strength with PC content as reported in the pervious section. The examination of the polarity of the PC/ABS matrices at varied composition of the blend was also 
performed for good understanding of their interaction with Kevlar. Figure 7 depicts variation in water contact angles of PC/ABS matrices at various compositions. In general, material with low water contact angle represents high polarity material and vice versa. From the figure, we observed a decrease of water contact angles of $\mathrm{PC} / \mathrm{ABS}$ matrices from $104^{\circ}$ of pure $\mathrm{ABS}$ to $88.4^{\circ}$ of pure $\mathrm{PC}$ i.e. the polarity of the $\mathrm{PC} / \mathrm{ABS}$ increases with increasing the $\mathrm{PC}$ content in the blend.

From the mechanical behaviors and the polarity of PC/ABS blend, it can be concluded that polarity of the Kevlar fiber (Solubility Parameter $(\delta)=23$ ) and the polycarbonate (Solubility Parameter $(\delta)=21$ ) trend to be closer to each other than that to of ABS [25]. Therefore, the Kevlar-reinforced composite with greater PC content in the matrix exhibits higher compatibility between the fiber and the matrix. This is the reason why the peel strength and the flexural properties of the composite increased with increasing the PC content in the matrix. The relationship between compatibility and the enhancement of mechanical properties in this study corresponds to those for other systems reported in the literatures [26-28].
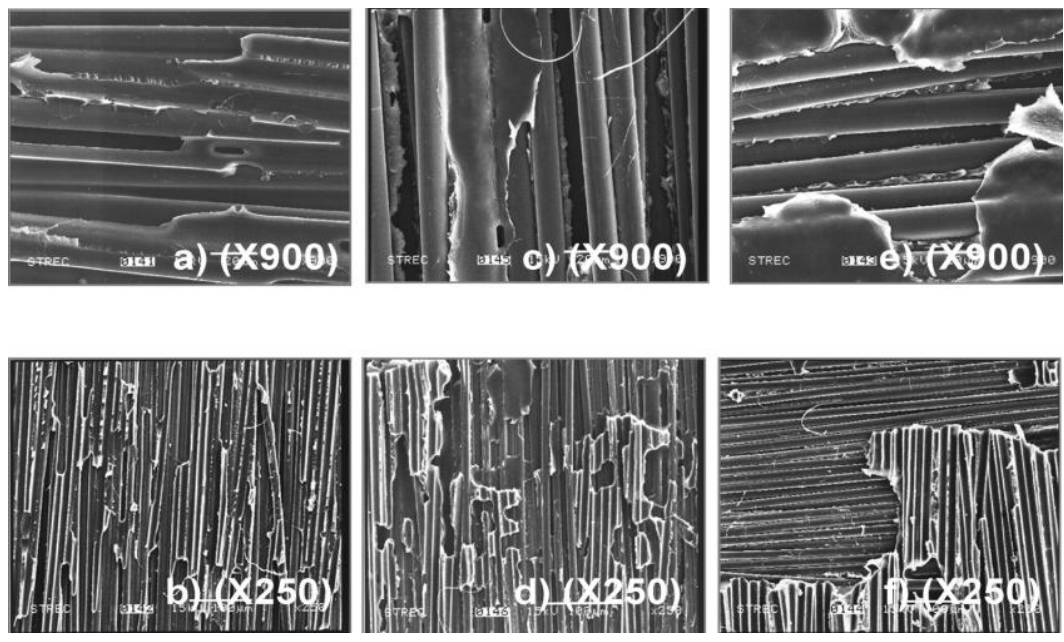

Fig. 8. SEM micrographs of Kevlar/PC/ABS composites at various matrix compositions: (a) and (b) pure ABS; (c) and (d) 40/60 PC/ABS; and (e) and (f) pure PC.

The morphologies of the peeled surfaces examined using SEM are shown in Figs. 8(a) to 8(f). The micrographs of the composite of ABS as matrix (Figs. 8(a) and 8(b)) exhibit high degree of interfacial failure implying that the fibers were easily stripped from the matrix material. It means that the adhesion between the Kevlar fibers and the ABS matrix is very poor. It can be seen from Figs. 8(e) and 8(f) that the composite used pure PC as a matrix rendered good adhesion between the Kevlar fiber and the matrix. This composite exhibited low interfacial or adhesive failure but rather high matrix failure i.e. cohesive failure. However, in Figs. 8(c) and 8(d), the composite with $40 \mathrm{wt} \%$ PC in the matrix displayed substantial degree of both matrix failure and interfacial failure. Moderate amount of stripped fibers was observed in this composite. It could be concluded that the Kevlar-reinforced 40/60 PC/ABS exhibited optimal level of interfacial interaction between the Kevlar fiber and the PC/ABS matrix for ballistic resistance.

\section{Conclusions}

In the matrix study, the flexural modulus of the PC/ABS alloys at various PC contents exhibited a positive deviation from the rule of mixing. The highest modulus value of $2.7 \mathrm{GPa}$ was observed in the PC:ABS ratio of 40:60. Furthermore, the flexural strength of PC/ABS alloys exhibited negative deviation from the mixing rule when the PC content was less than about $60 \mathrm{wt} \%$ of PC. The flexural strength then turned to positive deviation from the rule when the PC content was higher than $60 \mathrm{wt} \%$. The tensile strength of the alloys increased with increasing PC content from $46 \mathrm{MPa}$ (pure ABS) to 60 $\mathrm{MPa}$ (pure ABS). In addition, the increasing rate of tensile strength value was changed at the composition between 40 and $60 \mathrm{wt} \%$ of PC in the blend. In the composite system, the most optimum weight ratio of PC:ABS is 60:40. It was found that the flexural modulus and strength of Kevlar- 
reinforced PC/ABS composite are increased with matrix contents. Additionally, the flexural strength sharply increases with the matrix content and then reached the maximum value of $167 \mathrm{MPa}$ at the matrix content of $33.4 \mathrm{wt} \%$. From the peel test, it reveals that the interfacial adhesion between the Kevlar fiber and the polymer matrix could be improved by increasing the PC content in the matrix.

\section{Acknowledgements}

The authors would like to acknowledge the Thailand Research Fund (TRF) and the Higher Education Research Promotion and National Research University Project of Thailand, Office of the Higher Education Commission (AM1076A), for financial support of this project. Furthermore, additional supports are also provided by the $90^{\text {th }}$ Anniversary of Chulalongkorn University Fund and the Funding from Thailand Graduate Institute of Science and Technology, NSTDA. The authors also would like to thank Bayer Co., Ltd. and Lanxess (Thailand) Co., Ltd. for their support of raw materials.

\section{References}

[1] R. Greco and M. Iavarone, "Influence of low molecular weight ABS species on properties of PC/ABS systems," Polym. Eng. Sci., vol. 40, no. 7, pp. 1701-1715, Jul, 2000.

[2] D. R. Paul and J. W. Barlow, "Polymer Blends (or Alloys)," J. Macromol. Sci. - Rev. Macromol. Chem., vol. C18, pp.109-168, 1980.

[3] D. R. Paul, J. W. Barlow, and H. Keskkula, "Polymer Blends," in Encyclopedia of Polymer Sciences and Engineering, H. F. Mark et al., Eds., New York: Wiley, 1985, vol. 12, pp. 399461.

[4] L. A. Utracki, Polymer Blends Handbook, Kluwer Academic Publishers, MA, 2002, pp. 33.

[5] T. S. Grabowski, "Blends of polycarbonates with polybutadiene, styrene, acrylonitrile graft copolymers," U.S. Patent 3,130,177, Apr, 1964.

[6] D. E. Henton, and T. M. O'Brien, "Particle agglomeration in rubber lattices," U.S. Patent 4 419 496, Dec, 1983.

[7] H. L. Rawlings and E. R. Gerand, "Impact improvement of reinforced polycarbonate/ABS blends," U.S. Patent 4487 881, Dec, 1984.

[8] H.-C. Kao, M.-M. Lee, C.-C. Chiang, J.-L. Lin, and T.-K. Wu, "Heat stabilized ABSpolycarbonate polymer blend compositions," U.S. Patent 5055 505, Oct, 1991.

[9] K. Udipi, "Polymer blends of polycarbonate, PCTG and ABS," U.S. Patent 5082 897, Jan, 1992.

[10] R. Newmann, E. Baumgartner, K. Benker, and K. Ruppmich, "Thermoplastic molding materials having good low-temperature impact strength," U.S. Patent 5162 423, Nov, 1992.

[11] L. M. Gemmell, O. W. Tennant, and R. R. Gallucci, "Water absorbing polymers," U.S. Patent 5384 343, Jan, 1995.

[12] M. N. Machmud, D. Mochizuki, M. Omiya, H. Inoue, and K. Kishimoto, "High deformation rate and failure characteristics of amorphous polymers and their blends," Mater. Sci. Eng., A, vol. 483-484, pp. 242-244, June, 2008

[13] R. Greco and M. Iavarone, "Influence of low molecular weight ABS species on properties of PC/ABS systems," Polym. Eng. Sci., vol.40, no. 7, pp.1701-1715, Jul, 2000.

[14] R. Greco and M. Iavarone, "Influence of ABS low molecular weight species on ABS properties," Pure Appl. Chem., vol. 37, no. 1-2, pp. 1-14, Jan, 2000.

[15] R. Greco, and A. Sorrentino, "Polycarbonate/ABS blends: a literature review," Adv. Polym. Tech., vol. 13, no. 4, pp. 249-258, 1994.

[16] L. Dong, R. Greco, and G. Orsello, "Polycarbonate/acrylonitrile-butadiene-styrene blends: 1. Complementary etching techniques for morphology observations," Polymer, vol. 34, no. 7, pp. 1375-1382, 1993.

[17] N. Patel, "Carbon-reinforced PC-ABS composition and articles made from same," U.S. Patent 6231 788, May, 2001.

[18] C.-Y. Huang and C.-C. Wu, "The EMI shielding effectiveness of PC/ABS/nickel-coatedcarbon-fibre composites," Eur. Polym. J., vol. 36, no. 12, pp. 2729-2737, Dec, 2000. 
[19] S. Wang, Y. Hu, F. You, L. Song, Z. Chen, and W. Fan, "Self-assembly of polycarbonate/acrylonitrile-butadiene-styrene/montmorillonite nanocomposites," J. Appl. Polym. Sci., vol. 90, no. 5, pp. 1445 - 1446, Oct, 2003.

[20] H. H. Yang, Kevlar Aramid Fibers. West Sussex: John Wiley \& Sons, 1993.

[21] B. S. Lombardo, H. Keskkula, and D. R. Paul, "Influence of ABS type on morphology and mechanical properties of PC/ABS blends," J. Appl. Polym. Sci.,vol. 54, no. 11, pp. 1697$1720,1994$.

[22] N. B. Menon, D. Frank, and L. R. Dharani, "Use of titanate coupling agents in Kevlarphenolic composites," J. Appl. Polym.Sci., vol. 54, no. 1, pp. 113-123, 1994.

[23] E. T. N. Bisanda and M. P. Ansell, "The effect of silane treatment on the mechanical and physical properties of sisal-epoxy composites," Compos. Sci. Technol., vol. 41, no. 2, pp. 165178, 1991.

[24] B. Lim, C. Kim, B. Kim, U. Shim, S. Oh, B. Sung, J. Choi, and S. Baik, "The effects of interfacial bonding on mechanical properties of single-walled carbon nanotube reinforced copper matrix nanocomposites", Nanotechnology, vol. 17, no. 23, pp. 5759-5764, 2006.

[25] J. E. Mark, Physical Properties of Polymers Handbook. New York: Woodbury, 1996.

[26] B. A. Acha, M. M. Reboredo, and N. E. Marcovich, "Creep and dynamic mechanical behavior of PP-jute composites: Effect of the interfacial adhesion," Compos Part A-Appl S, vol. 38, pp.1507-1516, 2007.

[27] A. H. Wang, X. L. Zhang, X. F. Zhang, X. Y. Qiao, H. G. Xu, and C. S. Xie, "Ni-based alloy/submicron $\mathrm{WS}_{2}$ self-lubricating composite coating synthesized by Nd:YAG laser cladding," Mater. Sci. Eng., A, vol.475, no. 1-2, pp. 312-318, Feb, 2008.

[28] Y.-F. Shih, "Mechanical and thermal properties of waste water bamboo husk fiber reinforced epoxy composites," Mater. Sci. Eng., A, vol. 445-446, pp. 289-295, Feb, 2007. 